\title{
Implementasi POX pada Perangkat Lunak Software-Defined Networking Controller untuk Data Center Berbasis Container
}

\author{
Dhanar Prayoga, Royyana Muslim Ijtihadie, dan Muchammad Husni \\ Departemen Teknik Informatika, Fakultas Teknologi dan Informasi Institut Teknologi Sepuluh \\ Nopember \\ e-mail: roy@if.its.ac.id
}

\begin{abstract}
Abstrak-Software-Defined Networking( SDN) adalah arsitektur jaringan yang memisahkan antara control plane dan data plane sebuah jaringan, sehingga memungkinkan pengendalian jaringan dari sebuah SDN Controller. SDN Memungkinkan perubahan bentuk jaringan dengan konfigurasi minimal oleh administrator jaringan. Hal ini membuat arsitektur SDN sangat cocok untuk digunakan pada jaringan yang selalu berubah - ubah, salah satunya adalah data center virtual berbasis software container. Software Container adalah sebuah perangkat lunak yang mampu menggantikan virtual host pada sebuah virtual data center. Pada makalah ini akan dibuat sebuah SDN Controller yang dapat digunakan pada jaringan fisik maupun virtual, dengan orientasi sebuah data center berbasis software container. SDN Controller akan dibangun menggunakan POX, sebuah platform pengembangan SDN Controller. Hasil uji coba menunjukkan bahwa sistem yang dibangun mampu diimplementasikan pada jaringan virtual maupun jaringan fisik, serta mampu menangani jaringan yang memiliki looping.
\end{abstract}

Kata Kunci-Software-Defined Networking, Software Container, Data Center, POX.

\section{PENDAHULUAN}

$\mathrm{P}$ ERKEMBANGAN teknologi dewasa ini menunjukkan tren yang mengarah pada virtualisasi. Virtualisasi yang terjadi tidak hanya pada virtualisasi perangkat, namun juga virtualisasi jaringan (NV)[1] dan virtualisasi fungsi jaringan (NFV)[2] Virtualisasi memiliki banyak keuntungan dari berbagai sisi. Keuntungan, terutama dalam sisi ekonomi, membuat pasar memilih untuk memvirtualisasikan perangkat mereka ketimbang membeli dan memelihara perangkat secara tersendiri. Virtualisasi juga memiliki banyak permasalahan. Salah satu permasalahan yang dihadapi adalah permasalahan konfigurasi jaringan yang harus dilakukan setiap kali melakukan deploy perangkat virtual. Konfigurasi jaringan yang selalu berubah ini tidak memungkinkan network administrator untuk merubah konfigurasi jaringan setiap ada perangkat virtual baru, sehingga dapat disimpulkan dibutuhkan sebuah solusi yang mampu menjawab permasalahan ini.

Software-Defined Networking (SDN)[3] dapat menyelesaikan permasalahan yang dialami pada virtual data center. SDN adalah sebuah arsitektur jaringan yang memisahkan data plane dan control plane. Hal ini memungkinkan Network Administrator melakukan konfigurasi jaringan secara otomatis dan hanya mengakses sebuah SDN
Controller, sehingga memudahkan Network Administrator dalam mengelola jaringan.

POX[4] adalah sebuah platform berbasis bahasa pemrograman Python yang digunakan untuk mengembangkan perangkat lunak SDN Controller. POX memiliki beberapa komponen yang dapat digunakan ulang untuk membuat SDN Controller sesuai dengan kebutuhan pengguna. Hal ini memungkinkan untuk pembuatan perangkat lunak SDN Controller yang cocok untuk sebuah jaringan spesifik, contohnya virtual data center berbasis Software Container.

Makalah ini menawarkan sebuah solusi pembangunan SDN Controller menggunakan teknologi POX yang akan berjalan diatas jaringan virtual berbasis Mininet[5]. Penulis berharap perangkat lunak SDN Controller dapat menyelesaikan permasalahan konfigurasi jaringan yang dihadapi. Sehingga dapat membantu Network Administrator untuk melakukan konfigurasi jaringan yang optimal guna tercapainya optimasi virtualisasi perangkat.

\section{STUDI LITERATUR}

A. $P O X$

POX adalah sebuah platform pengembangan perangkat lunak SDN Controller berbasis bahasa pemrograman Python. POX memiliki beberapa komponen yang dapat digunakan dan digabung untuk membentuk SDN Controller sesuai kebutuhan pengguna.

\section{B. Containernet}

Containernet adalah modifikasi dari Mininet[5] yang mampu menggunakan Software Container sebagai host. Containernet menambahkan beberapa fungsionalitas dari Mininet yang terkait dengan software container, seperti pengaturan jaringan container, alokasi sumber daya container, penggantian topologi on-the-fly, kontrol trafik, dan lain lain. Containernet merupakan hasil penelitian Manuel Peuster, Holger Karl, dam Steven van Rossem yang berjudul "MeDICINE: Rapid Prototyping of Production-Ready Network Services in Multi-PoP Environments." Yang muncul di konferensi IEEE tentang Network Function Virtualization and Software Defined Network (NFV-SDN), 2016[6].

\section{FLASK}

FLASK[7] adalah sebuah kerangka kerja mikro aplikasi web 
yang dibangun dari Jinja2, Werkzeug, dan dilisensi dengan lisensi BSD[18]. Flask dibangun diatas bahasa pemrograman Python.

\section{DESAIN UMUM SISTEM}

Arsitektur sistem dapat dilihat pada Gambar 2. Gambar 2 menunjukkan arsitektur sistem yang dibangun. Sistem yang dibangun ada didalam kotak "sistem", sedangkan entitas diluar "sistem" adalah entitas yang akan saling berinteraksi dengan sistem, namun tidak dibuat dalam makalah ini. SDN Controller yang dibangun akan mengatur fungsi routing pada jaringan fisik (MikroTik) maupun jaringan virtual (virtual data center). Selain itu akan dibangun Web Server API yang dapat digunakan membangun website untuk membuat jaringan virtual berbasis Containernet[6] untuk membangun virtual data center berbasis software container. Web Sever API akan dibangun dengan bahasa pemrograman Python menggunakan kerangka kerja FLASK.

Desain SDN Controller dapat dilihat pada Gambar 1. SDN Controller dibangun dari komponen yang disediakan oleh platform POX. Platform yang digunakan ada 3, yaitu Discovery, Spanning_Tree, dan L2_Learning. Komponen Discovery digunakan untuk terus - menerus mendeteksi bentuk jaringan, sehingga SDN Controller dapat mengetahui bentuk jaringan beserta perubahannya. Hasil dari komponen Discovery akan digunakan oleh komponen Spanning_Tree, yang akan membentuk sebuah spanning tree dari jaringan dengan cara menutup port yang tidak dibutuhkan. Komponen ini digunakan untuk mengatasi looping pada jaringan, sebuah kasus yang sangat mungkin terjadi. Komponen terakhir yaitu komponen L2_Learning, yaitu komponen forwarding. Komponen ini dipilih karena jaringan yang selalu berubah membutuhkan algoritma forwarding yang memiliki timeout.

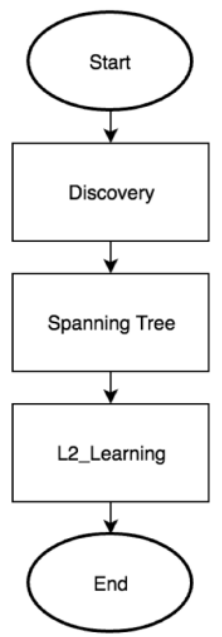

Gambar 1. Desain SDN Controller

Proses implementasi sistem pada jaringan virtual dilakukan untuk merubah bentuk perintah jaringan yang sinkron menjadi asinkron. Hal ini dicapai dengan mengimplementasikan task scheduler yaitu Celery[8]. Dalam mengimplementasikan Celery, dibutuhkan sebuah message queue seperti Redis[9].

Proses implementasi sistem pada jaringan fisik membutuhkan aktivasi fitur OpenFlow[10] pada switch. Hal ini dapat dilakukan dengan pemasangan perangkat lunak RouterOS ataupun OpenWRT pada switch.

Desain SDN Controller dapat dilihat pada Gambar 1. SDN Controller dibangun dari komponen yang disediakan oleh platform POX. Platform yang digunakan ada 3, yaitu Discovery, Spanning_Tree, dan L2_Learning. Komponen Discovery digunakan untuk terus - menerus mendeteksi bentuk jaringan, sehingga SDN Controller dapat mengetahui bentuk jaringan beserta perubahannya. Hasil dari komponen Discovery akan digunakan oleh komponen Spanning_Tree, yang akan membentuk sebuah spanning tree dari jaringan dengan cara menutup port yang tidak dibutuhkan. Komponen ini digunakan untuk mengatasi looping pada jaringan, sebuah kasus yang sangat mungkin terjadi. Komponen terakhir yaitu komponen L2_Learning, yaitu komponen forwarding. Komponen ini dipilih karena jaringan yang selalu berubah membutuhkan algoritma forwarding yang memiliki timeout.

\section{UJI COBA DAN PEMBAHASAN}

\section{A. Skenario Uji Coba}

Pengujian sistem bertujuan untuk mengetahui performa dari sistem yang dibangun. Pengujian dilakukan dengan melakukan uji coba kecepatan jaringan, baik pada jaringan fisik maupun jaringan virtual.

Tabel 1 merupakan skenario uji coba yang dilakukan. Skenario uji coba adalah perbedaan bentuk jaringan virtual maupun fisik, jumlah switch yang ada pada jaringan, maupun bentuk topologi jaringan terhadap kecepatan jaringan. Pengujian dilakukan dengan menggunakan kakas iperf[11]. Pada jaringan virtual, iperf server dan client dijalankan pada Ubuntu pada sebuah Container.

\section{B. Hasil Uji Coba dan Pembahasan}

Gambar 3 adalah hasil dari masing masing pengujian. Terlihat bahwa terdapat perbedaan kecepatan antara jaringan virtual dan jaringan fisik. Selain itu, kecepatan jaringan juga dipengaruhi oleh banyaknya hops yang harus dilewati antara iperf client dengan iperf server. Keberhasilan skenario pengujian SP-04 menunjukkan bahwa sistem yang dibangun mampu diimplementasikan pada jaringan yang memiliki looping.

Tabel 1.

Skenario Pengujian Performa

\begin{tabular}{lllll}
\hline \hline Skenario & Bentuk & Perangkat & Jumlah & Topologi \\
Pengujian & jaringan & Lunak Switch & Switch & Jaringan \\
\hline SP-01 & Virtual & Containernet & 2 & Line \\
SP-02 & Virtual & Containernet & 20 & Line \\
SP-03 & Virtual & Containernet & 100 & Line \\
SP-04 & Virtual & Containernet & 20 & Fully \\
& & & & Connected \\
& & & & Mesh \\
SP-05 & Fisik & RouterOS & 1 & Line \\
SP-06 & Fisik & OpenWRT & 1 & Line \\
\hline \hline
\end{tabular}




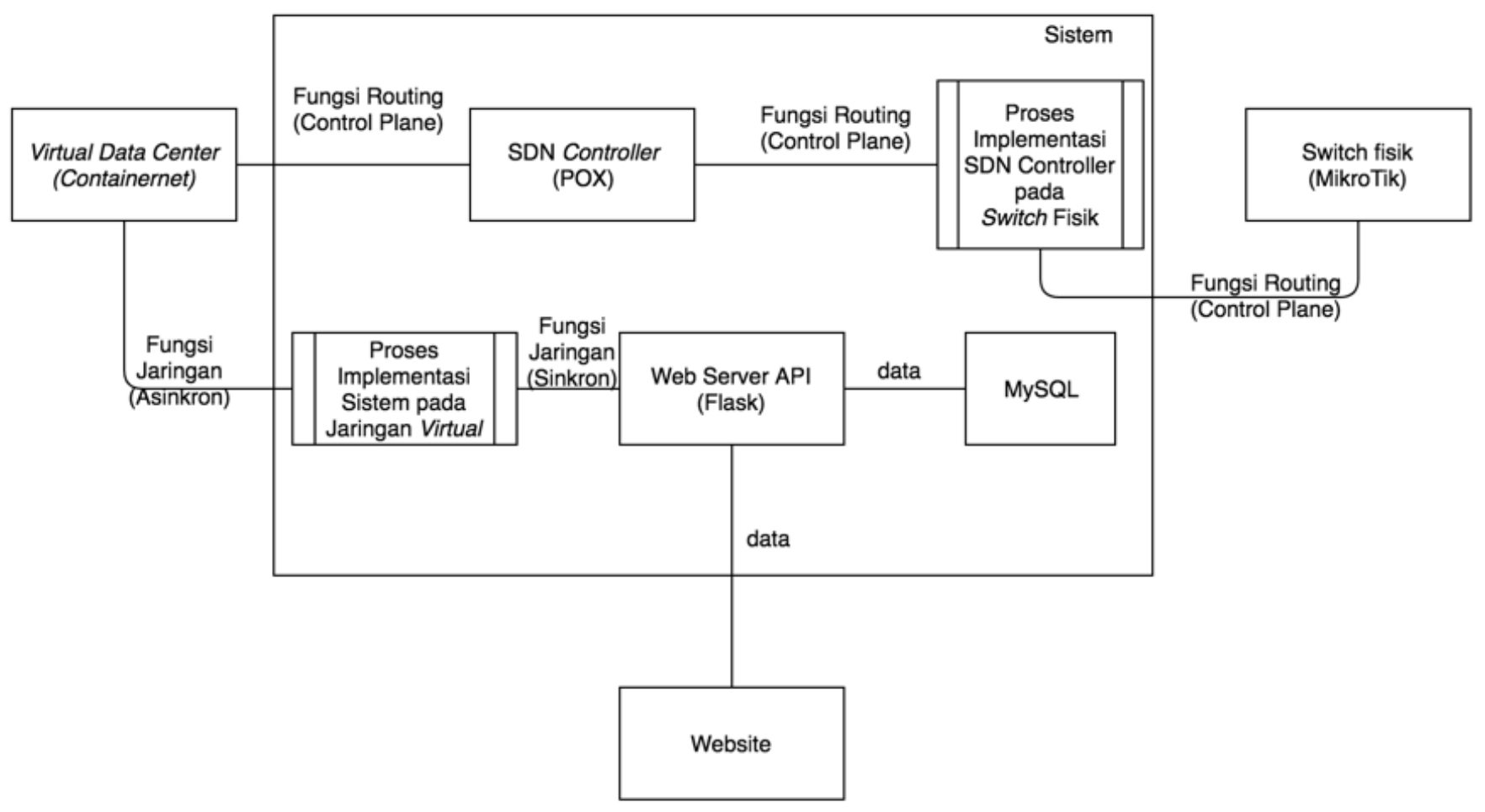

Gambar 2. Desain arsitektur sistem

Hasil Pengujian Performa Rata- Rata SDN Controller

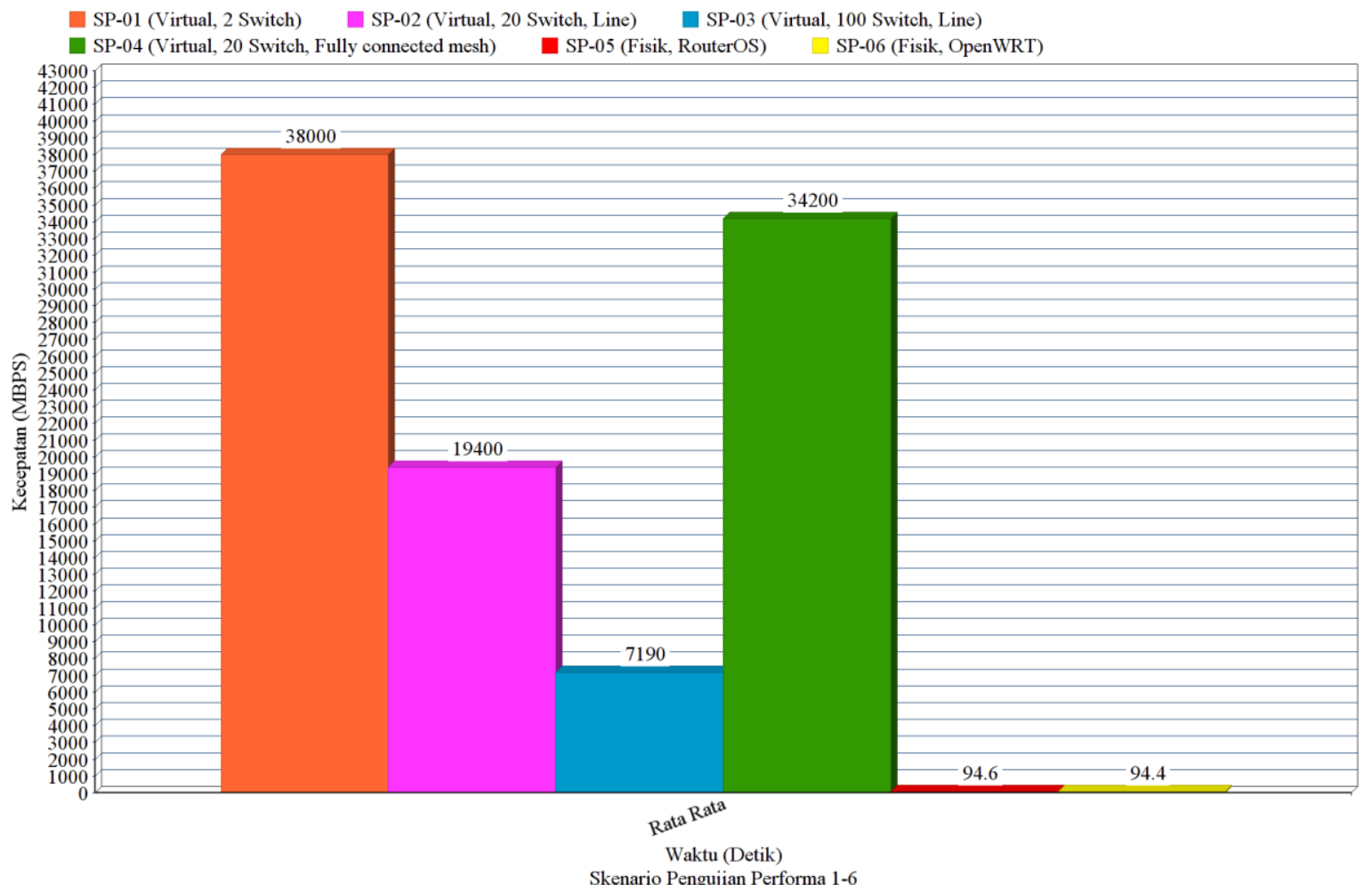

Gambar 3. Hasil uji coba 


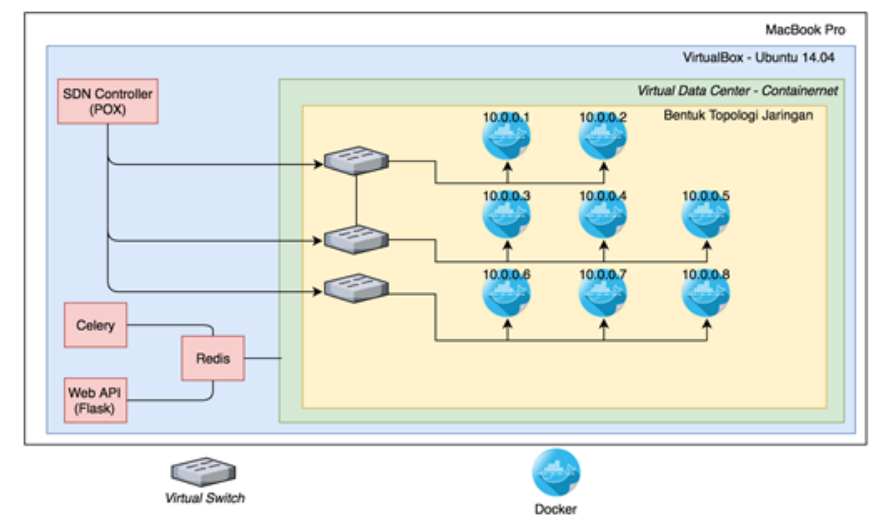

Gambar 4. Arsitektur Uji Coba

\section{KESIMPULAN/RINGKASAN}

Sistem yang dibangun berhasil diimplementasikan pada jaringan fisik maupun jaringan virtual. POX dapat digunakan untuk membangun SDN Controller yang diimplementasikan pada jaringan fisik maupun virtual. Jaringan virtual dapat dibangun menggunakan platform Containernet dan dapat digunakan untuk membangun virtual data center berbasis software container. Kecepatan jaringan bergantung pada bentuk jaringan yaitu fisik atau virtual. Selain itu, kecepatan jaringan juga dipengaruhi oleh banyaknya hops yang harus dilewati, sehingga bentuk topologi jaringan sangat mempengaruhi kecepatan jaringan.

\section{DAFTAR PUSTAKA}

[1] "What Is a Virtual Network?," SDxCentral, 10-May-2016. [Online]. Available: https://www.sdxcentral.com/sdn/networkvirtualization/definitions/what-is-a-virtual-network/. [Accessed: 02May-2017].

[2] "What's Network Functions Virtualization (NFV)?," SDxCentral, 25Aug-2013. [Online]. Available: https://www.sdxcentral.com/nfv/definitions/whats-networkfunctions-virtualization-nfv/. [Accessed: 14-Jul-2017].

[3] "Software-Defined Networking (SDN) Definition - Open Networking Foundation." [Online]. Available: https://www.opennetworking.org/sdn-resources/sdn-definition. [Accessed: 14-Dec-2016].

[4] "noxrepo/pox," GitHub. [Online]. Available: https://github.com/noxrepo/pox. [Accessed: 14-Dec-2016].

[5] "Mininet Overview - Mininet," Mininet. [Online]. Available: http://mininet.org/overview/. [Accessed: 14-Dec-2016].

[6] M. Peuster, H. Karl, and S. van Rossem, "MeDICINE: Rapid prototyping of production-ready network services in multi-PoP environments," in 2016 IEEE Conference on Network Function Virtualization and Software Defined Networks (NFV-SDN), 2016, pp. 148-153.

[7] "Welcome | Flask (A Python Microframework)." [Online]. Available: http://flask.pocoo.org/. [Accessed: 03-May-2017].

[8] "Homepage | Celery: Distributed Task Queue." [Online]. Available: http://www.celeryproject.org/. [Accessed: 04-May-2017].

[9] "Redis." [Online]. Available: https://redis.io/. [Accessed: 04-May2017].

[10] "OpenFlow - Open Networking Foundation." [Online]. Available: https://www.opennetworking.org/sdn-resources/openflow. [Accessed: 14-Jul-2017].

[11] "iPerf - The TCP, UDP and SCTP network bandwidth measurement tool." [Online]. Available: https://iperf.fr/. [Accessed: 30-May-2017]. 